\title{
Sex differences in spatial learning and memory and hippocampal long-term potentiation at perforant pathway-dentate gyrus (PP-DG) synapses in Wistar rats
}

\author{
Samaneh Safari ${ }^{1 \dagger}$, Nesa Ahmadi ${ }^{1 \dagger}$, Reihaneh Mohammadkhani ${ }^{1}$, Reza Ghahremani ${ }^{1,2}$, \\ Maryam Khajvand-Abedeni ${ }^{1}$, Siamak Shahidi ${ }^{1,3}$, Alireza Komaki ${ }^{1,3}$, Iraj Salehi ${ }^{1}$ and Seyed Asaad Karimi ${ }^{1,3^{*}}$ (i)
}

\begin{abstract}
Background: Recent studies show that gender may have a significant impact on brain functions. However, the reports of sex effects on spatial ability and synaptic plasticity in rodents are divergent and controversial. Here spatial learning and memory was measured in male and female rats by using Morris water maze (MWM) task. Moreover, to assess sex difference in hippocampal synaptic plasticity we examined hippocampal long-term potentiation (LTP) at perforant pathway-dentate gyrus (PP-DG) synapses.
\end{abstract}

Results: In MWM task, male rats outperformed female rats, as they had significantly shorter swim distance and escape latency to find the hidden platform during training days. During spatial reference memory test, female rats spent less time and traveled less distance in the target zone. Male rats also had larger LTP at PP-DG synapses, which was evident in the high magnitude of population spike (PS) potentiation and the field excitatory post synaptic potentials (fEPSP) slope.

Conclusions: Taken together, our results suggest that sex differences in the LTP at PP-DG synapses, possibly contribute to the observed sex difference in spatial learning and memory.

Keywords: Long-term potentiation, Hippocampus, Dentate Gyrus, Spatial learning and memory, Sex difference, Wistar Rat

\section{Background}

Male and female nervous system respond differently to abnormal physiological situations [1], so finding sex differences in diverse brain functions seems essential. Studies have shown that gender may have a substantial effect on human cognitive ability [2]. Men and women appear

*Correspondence: asad_karimi_128@yahoo.com; a.karimi@umsha.ac.ir; asadkarimi@sbmu.ac.ir

'Samaneh Safari and Nesa Ahmadi contributed equally to this work

${ }^{1}$ Neurophysiology Research Center, Hamadan University of Medical Sciences, Hamadan, Iran

Full list of author information is available at the end of the article to have different strategies for decision-making and memory encoding. Because the nervous system controls cognitive behaviour, these sex-related functional differences may be associated to the sex-specific structure of the neuronal circuits in the nervous system [3].

Spatial memory is responsible for spatial orientation and retrieving information about the locations of objects and places in the environment [4]. Gender differences in cognition have been described in cognitive and behavioral psychology for many years [5]. Moreover, several studies have reported sex differences in spatial ability in humans, primates, and rodents $[4,6-10]$. Overall, males original author(s) and the source, provide a link to the Creative Commons licence, and indicate if changes were made. The images or other third party material in this article are included in the article's Creative Commons licence, unless indicated otherwise in a credit line to the material. If material is not included in the article's Creative Commons licence and your intended use is not permitted by statutory regulation or exceeds the permitted use, you will need to obtain permission directly from the copyright holder. To view a copy of this licence, visit http://creativecommons.org/licenses/by/4.0/. The Creative Commons Public Domain Dedication waiver (http://creativecommons.org/publicdomain/zero/1.0/) applies to the data made available in this article, unless otherwise stated in a credit line to the data. 
excel in spatial processing, while females excel in verbal work [11-14]. Also. studies on rodents and humans have shown that males have better performance on spatial memory tasks to females [4, 15-17].

On the other hand, some groups claim that there is no gender difference in spatial memory ability [18-20]. According to the literature, the results seem to be varied and divisive, from "substantial difference" to "no significant difference". In the current work, we first attempted to determine sex differences in spatial memory and sought to find possible underlying mechanisms in rats.

Some works have shown that the brain areas related with spatial anility can be different in each sex or have different functions [21-25]. Nevertheless, the main neural circuits and underlying mechanisms responsible for these differences are not fully understood and there are contradictions in this regard.

There is much evidence that the hippocampus plays an important role for long-term memory and is necessary for episodic and spatial memory [26-28]. The hippocampus shows high degree of synaptic plasticity. Two main classes of synaptic plasticity are long-term potentiation (LTP) and long-term depression (LTD). It is well wellknown that hippocampal LTP is the essential mechanism for spatial memory $[29,30]$. On the other hand, due to the main role of LTP in memory, differences in the induction or expression of LTP between males and females may be the cause of gender differences in spatial memory.

There is controversy about sex differences in synaptic plasticity. Strong sex differences in LTP induction have been reported in dentate gyrus (DG) of pentobarbital and/or urethane-anesthetized rats [31,32] and also in CA1 region of hippocampal slices [33-35]. However, some studies have reported no difference in LTP at the perforant pathway (PP)-DG synapses [36, 37]. It has been reported that the LTP magnitude is not different depending on the sex $[35,37]$. Stephen et al. have reported sex differences in hippocampal LTP, but their results showed that, unlike sex difference in field excitatory post synaptic potentials (fEPSP) slope LTP, a sex difference in population spike (PS) amplitude LTP was not apparent [32]. Monfort et al. have also shown that hippocampal LTP in the CA1 region is reduced in mature compared to young male rats but not in female rats [38]. In our opinion, these findings should be repeated because there is no consistency in the literature about sex differences in cognitive functions such as spatial learning and memory and LTP. Therefore, the aim of the current work was to evaluate whether is there a difference between male and female rats in spatial learning and memory in the Morris water maze (MWM)? And whether changes in spatial learning and memory are related to hippocampal LTP at PP-DG synapses.

\section{Results}

Behavior

\section{Memory acquisition in MWM}

The time to locate the hidden platform or swim distance in training days decreased in both male and female rats. This means that the performance of animals improved during the 4-day training period. Figure 1 shows the data for the swimming distance to find the hidden platform. There was a significant main effect of training day on swim distance $[\mathrm{F}(1.623,22.72)=56.59, \mathrm{P}<0.0001]$. In general, male rats had shorter swimming paths to escape onto the hidden platform $(\mathrm{P}<0.05)$, indicating that males had better performance than females. Escape latency to find hidden platform (Fig. 2.) increased in female animals when compared with male rats. There was a significant main effect of training day on escape latency [F (2.562, $35.87)=23.22, \mathrm{P}<0.0001]$. Overall, male rats had shorter escape latency to find the hidden platform, indicating that males had better performance than females.

\section{Probe trial performance in MWM}

The probe test was performed $24 \mathrm{~h}$ after the last training trial test on day 5 to assess the reference memory. During this test, the platform was removed and swimming speed, time spent and distance traveled in target zone of the MWM were recorded. These data are shown in Fig. 3. Female rats spent less time in the target zone in compare with male animals (female rats: $13.83 \pm 2.04 \mathrm{~s}$, male: $20.35 \pm 1.03 \mathrm{~s}, \quad\left(\mathrm{t}_{14}=3.03, \mathrm{P}=0.025\right.$, Fig. 3a). Female rats traveled less distance in the target zone

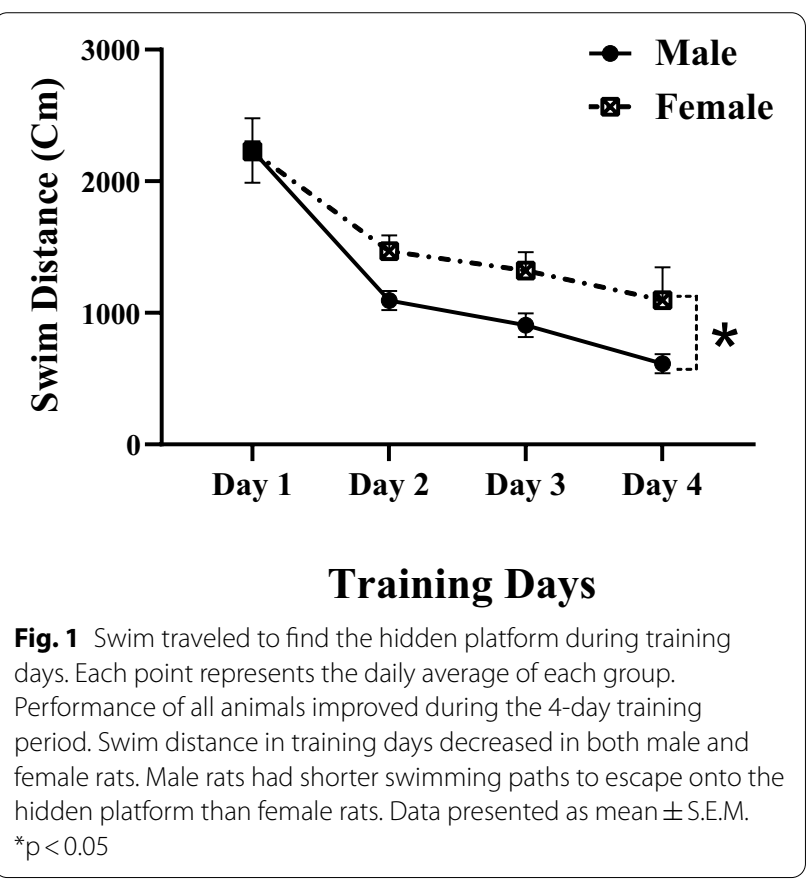




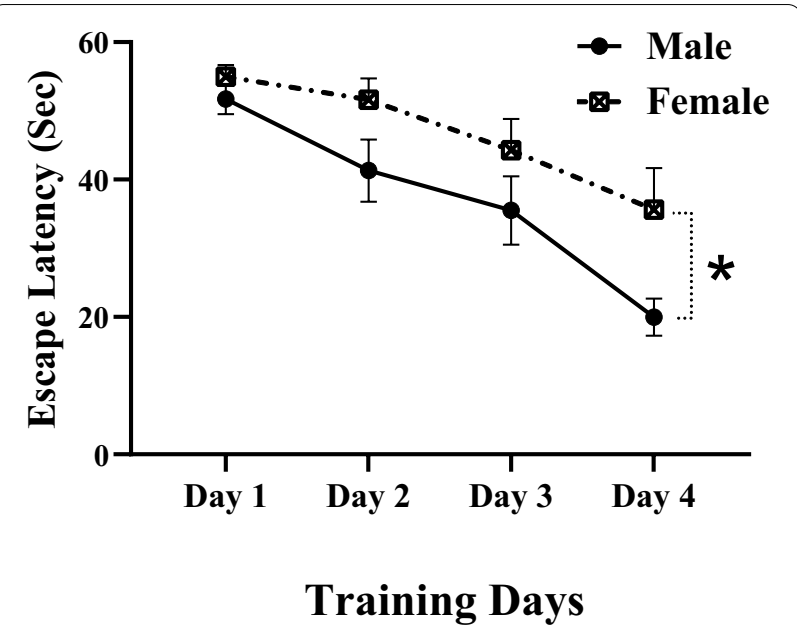

Fig. 2 Latency to find a hidden platform during training days. Each point represents the daily average of each group. Performance of all animals improved during the 4-day training period. The time to locate the hidden platform decreased in both male and female rats. Male rats had less latency to escape onto the hidden platform than female rats. Data presented as mean \pm S.E.M. ${ }^{*} p<0.05$

in compare with male animals $\left(\mathrm{t}_{14}=2.38, \mathrm{P}=0.03\right.$, Fig. 3b). Considering that in the probe test, the swimming speed was the same in male and female animals, it can be concluded that there are no motor disorders in these animals $\left(t_{14}=0.6369, P=0.5361\right.$, Fig. $\left.3 b\right)$. In the visible experiment that took place after the probe test, all the animals were able to find the platform. The results showed that there was no visual impairment in the animals because the escape latencies to find the visible platform during visible experiment were the same in male and female rats (Fig. 4, P >0.05).

\section{LTP at PP-DG synapses}

We studied LTP at PP-DG synapses in urethane-anesthetized rats to evaluate sex differences in hippocampal synaptic plasticity. Male and female rats were tested for probable differences in PP-DG LTP induction. Before and after high frequency stimulation in PP, the extracellular field potentials were recorded in the DG area. LTP was determined by examining HFS-induced changes in the fEPSP slope and PS amplitude. Representative traces of LTP recording are shown in the upper panel of Fig. 5.

\section{Excitatory postsynaptic potential LTP}

As shown in Fig. 5, the magnitude of fEPSP slope LTP varied with sex of the rats. Two-way repeated-measures ANOVA revealed significant effect of time- points [F $(1.393,15.32)=15.05, \mathrm{P}=0.0006]$, significant effect of sex $[\mathrm{F}(1,11)=5.921, \mathrm{P}=0.0332]$, and a significant interaction of the two $[\mathrm{F}(3,33)=4.869, \mathrm{P}=0.0065]$ in slope of fEPSP of the granular cell of DG (Fig. 5). Post-hoc comparisons $(\mathrm{P}<0.05)$ indicated that males exhibited significantly more fEPSP slope LTP than female rats. The percentage change in fEPSP slope after HFS was significantly lower in female rats than in male rats.

\section{Population spike LTP}

The sex difference in PS amplitude LTP was also evident, as shown in Fig. 6. Two-way repeated-measures ANOVA revealed significant effect of time- points $[F$ (1.393, $15.32)=15.05, P=0.0006]$, significant effect of sex $[F$ $(1,11)=5.921, P=0.0332]$, and a significant interaction
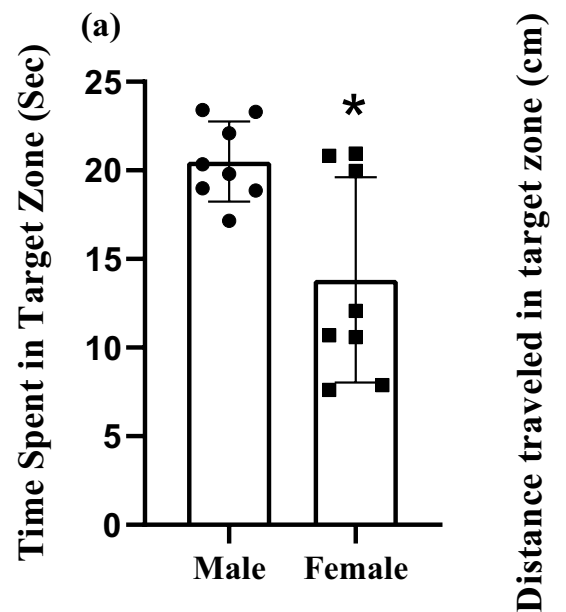

(b)

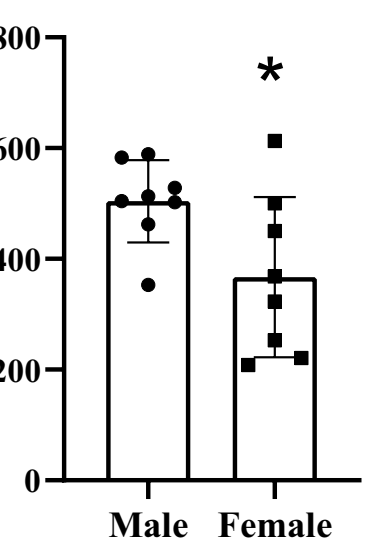

(c)

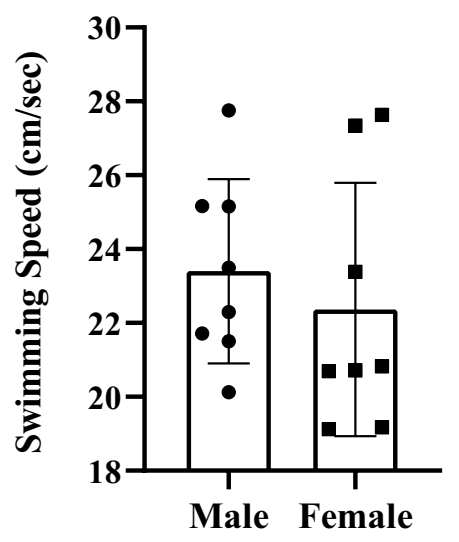

Fig. 3 Probe trial performance of male and female rats. Female rats spent less time $\mathbf{a}$ and traveled less distance $\mathbf{b}$ in the target zone. Swimming speed was same in both male and female animals (c). Data presented as mean \pm S.E.M. ${ }^{*} p<0.05$ 


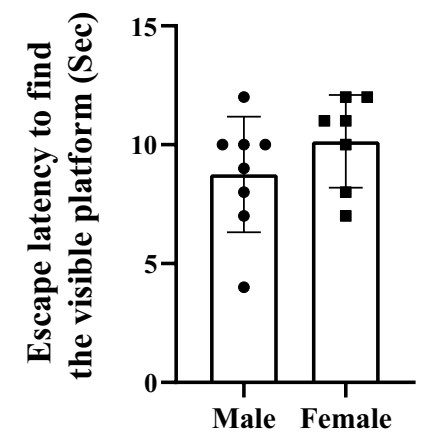

Fig. 4 Latency to escape onto the visible platform during visible experiment. There was no visual impairment in the animals because the escape latencies to find the visible platform during visible experiment were the same in male and female rats. Data presented as mean \pm S.E.M of the two $[\mathrm{F}(3,33)=4.869, \mathrm{P}=0.0065]$ in amplitude of PS in the granular cell of DG (Fig. 6). Post-hoc comparisons $(\mathrm{P}<0.0001)$ indicated that male rats exhibited significantly more PS amplitude LTP than female rats. The percentage change in PS amplitude after HFS was significantly lower in female rats than in male rats.

\section{Discussion}

The present study investigated sex differences in spatial ability and synaptic plasticity. Overall, male rats had a better performance than female rats in MWM task. Sex differences in LTP were also evident in the PS amplitude and the slope of fEPSP at PP-DG synapses. Male rats exhibited significantly more PS amplitude and fEPSP slope than female rats. Our data in the current work, using Wistar rats, are consistent with most other works showing that male rats had a better performance than female rats in MWM task.

There is controversy about sex differences in synaptic plasticity. For example, sex differences in LTP induction
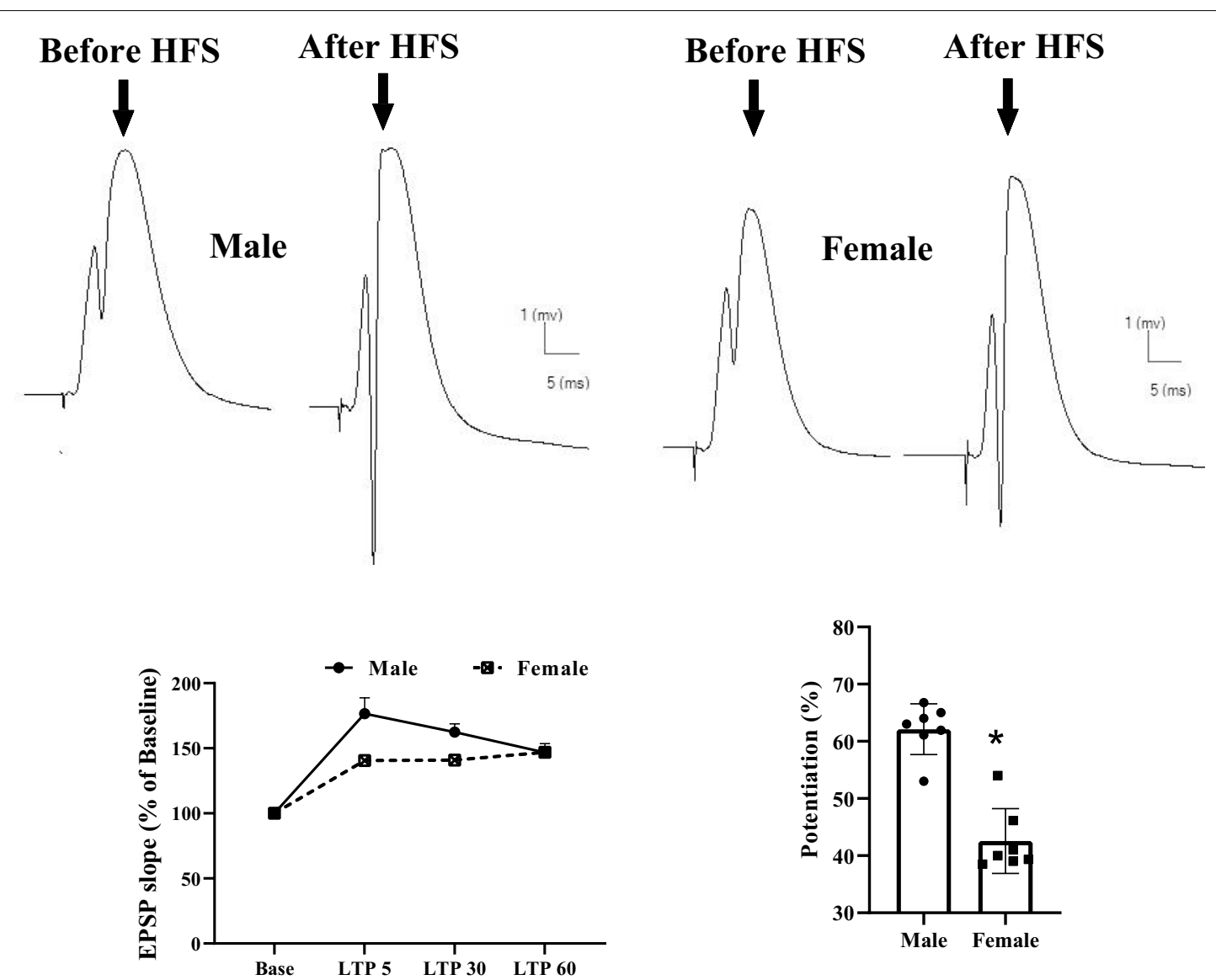

Fig. 5 Time-dependent variations in hippocampal evoked responses to PP stimulation following an HFS. Upper panel shows representative traces of evoked field potential recording in the DG area prior to and $60 \mathrm{~min}$ after HFS. Male rats exhibited significantly more fEPSP slope LTP than females. Left lower panel shows fEPSP slope change (\%) vs. time following HFS in both sex of rats. Bar graphs show the average fEPSP slope change (\%) during 60 min post-HFS. Data are expressed as means \pm SEM \% of baseline. ${ }^{*} P<0.05$ 

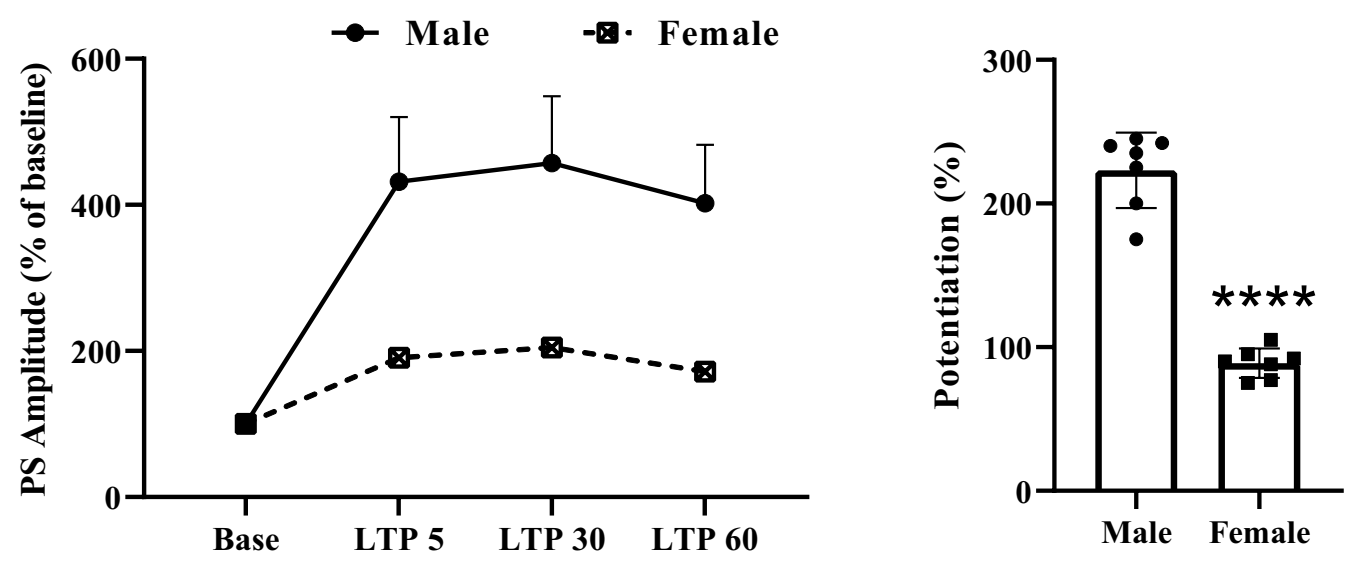

Fig. 6 Time-dependent variations in hippocampal evoked responses to PP stimulation following an HFS. Male rats exhibited significantly more PS amplitude LTP than females. Left panel shows PS amplitude change (\%) vs. time following HFS in both sex of rats. Bar graphs show the average PS amplitude change (\%) during 60 min post-HFS. Data are expressed as means \pm SEM $\%$ of baseline. *P $<0.0001$

have been reported in DG [31,32] and in CA1 [33-35]. Furthermore, it has been reported that the LTP magnitude is not different between males and females [35, 37]. Also, study by Chen et al. Showed that amygdala LTP is higher in female mice than male mice [39]. On the other hand, it has been reported that there is no sex difference for LTP in the amygdala [40]. These different observation on sex differences in synaptic plasticity may be due to different LTP recording protocols or recording in different brain areas.

An important difference in spatial learning and memory between male and female rats appears to be that they use different learning approaches that are controlled by different areas of the brain. The preference of adult male rats is a hippocampal-dependent spatial strategy rather than a striatum-dependent response strategy. In contrast, female rats prefer a spatial strategy only when the concentration of estradiol in their bloodstream increases [41].

Sex differences in hippocampal-related behaviors suggest that there may be differences in the organization and function of hippocampal neural circuits in males and females. Some studies have reported that the male hippocampus is larger than women [42, 43], although other studies have not shown such results [44-47].

Female rats display a reduced hippocampal LTP compared to males. These changes may be related to the modulation of glutamatergic synaptic transmission and in particular the function of N-methyl-D-aspartic acid (NMDA) receptors and synaptic plasticity by estrogens [48-50]. Estradiol has been shown to affect synaptogenesis and dendritic spine density in the hippocampus in female mice. Males treated with estradiol did not show an increase in hippocampal spine density, so it can be claimed that this effect is specific to females [50]. Modulation of synaptic plasticity by estrogens may be responsible for sex differences in synaptic plasticity and lower LTP in female rats. In males, overexpression of NMDA receptors may lead to higher $\mathrm{Ca}^{2+}$ entry and facilitate LTP induction [51]. NMDA receptors play a main role in both LTP and spatial learning and memory [52-54].

It has also been reported that changes in the number of AMPA receptors, their subunit composition, and phosphorylation state can alter synaptic plasticity [55]. AMPA receptor function and trafficking play an important role in LTP. In females, lower trafficking of AMPA receptors in the synaptic membrane may be responsible for lower LTP [34]. The lower trafficking and insertion of AMPA receptors is due to lower activation of cGMP-dependent protein kinase (PKG) [34]. PKG inhibition prevents the insertion of AMPA receptors into membranes, resulting in a decrease in hippocampal LTP [56].

One of the reasons for the low ability of females in spatial learning and memory is lower magnitude of LTP in females, and mechanisms that reduce LTP may also be involved in low performance of females in MWM task. Because both LTP and spatial learning are disrupted by inhibition of NMDA receptors [57, 58]. Impairment in LTP and impaired spatial learning and working memory have also been reported in mice lacking the GluR-A (GluR1) AMPA receptor subunit [59].

Also, sex differences in spatial ability appear to be related to stress [60]. And female performance in the MWM may be more sensitive to stress. No sex differences in spatial performance were observed when the rats were pre-exposed to the environment [61, 62]. Preexposure of animals to the MWM apparatus and testing procedures before hidden platform training has been 
shown to reduce or eliminate sex differences in MWM performance and response to stress. Pre-exposure to MWM apparatus and testing procedures reduces stress and stress-related hormones (e.g. corticosterone) during the test, and females may have better performance in less stressful situations $[63,64]$. It has also been shown that reversing the stress response by performing an adrenalectomy eliminates sex difference in MWM performance [63].

Higher thigmotaxis levels in the MWM test in females could be another cause of sex differences in spatial ability $[62,63,65,66]$. Also, it has been shown that after MWM test, the level of thigmotaxis is positively associated with the level of corticosterone, and pre-exposure to MWM apparatus and testing procedures reduces thigmotaxis $[63,67]$. The location of the platform is not the outer edge of the MWM tank,so MWM performance may be indirectly disrupted by thigmotaxis $[67,68]$.

It is important to understand that there is a link between estradiol levels in females and better performance in spatial skills, so that lower estradiol levels in females lead to better performance in rodents and in women $[69,70]$. Since stress rises estradiol levels in females [71], this stress exposure may increase estradiol levels and lead to poorer performance in females than males.

Another possible mechanism for better performance of male rats than females is that calcium/calmodulindependent protein kinase kinase $\beta$ (CaMKK $\beta)$ has an male-specific role in the processes of memory formation [72]. Additionally, CaMKK $\beta$ has been revealed to be essential for the activation of hippocampal cyclic AMPresponsive element binding protein (CREB) by spatial training, and to contribute to hippocampal LTP in male mice [73]. These observations suggest that hippocampal memory consolidation mechanisms are different between the sexes.

LTP has been reported to be dependent on nitric oxide synthase-1 (aNOS1) signaling in males (but not in females) [74]. Lack of nitric oxide (NO) and decreased hippocampal NOS1 expression in the female are the main causes of this sex difference [74]. However, NO-dependent LTP appears to be a secondary mechanism for LTP induction in females, but is more important in males.

\section{Conclusion}

In summary, our results showed that there was sex difference in LTP in PP-DG synapses, which was higher in male than female rats. Therefore, our study suggests that sex associated difference in LTP may contribute to sex difference in spatial learning and memory. Lack of determination of the estrous cycle stage and the corticosterone levels may be limitations of the present study, which should be considered in future studies.

\section{Methods \\ Animals and ethics statement}

In the present study, 2-month-old male and female Wistar rats were used. A total of 15 male ( 8 for MWM and 7 for electrophysiology) and 15 female (8 for MWM and 7 for electrophysiology) rats were used. The housing conditions of rats were as follows: Room temperature: $22 \pm 2{ }^{\circ} \mathrm{C}$; Light-dark cycles: (12 h light- $12 \mathrm{~h}$ dark); The number of rats per cage: $2-3$ rats; Access to food and water: free access to tap water and standard laboratory chow. The Animal Study Ethics Committee of our university approved all the experimental procedures used in this study. Also, all experimental procedures were done in accordance with the National Institutes of Health Guide for Care and Use of Laboratory Animals. Every effort was made to minimize suffering. Actions that can cause pain and distress were done in the absence of other animals in another room. Intraperitoneal injection of urethane (ethyl carbamate, $1.5 \mathrm{~g} / \mathrm{kg}$; i.p.) was used for anaesthetization of rats.

\section{Morris water maze (MWM) task \\ Apparatus}

The MWM test, a hippocampal-dependent test, is used to assess spatial learning and memory in rodents [7578]. The main advantage of MWM task is the distinction between spatial conditions (hidden platform) and non-spatial conditions (visible platform). Furthermore, the MWM test environment decreases odor trail interference. The MWM device consisted of a black circular pool with a diameter of $155 \mathrm{~cm}$ and a height of $60 \mathrm{~cm}$, which was filled with water at a temperature of $22 \pm 1{ }^{\circ} \mathrm{C}$ to a depth of $35 \mathrm{~cm}$. The pool was divided into four equal quadrants. An invisible platform with a diameter of $10 \mathrm{~cm}$, made of clear Plexiglas, was placed in the center of the eastern quarter as the target quadrant at a distance of $2 \mathrm{~cm}$ below the water surface. A video-computer tracking system (CCD camera, Panasonic Inc., Japan) was used to record the rats' swim path for further analysis (EthoVision software XT7, Netherland). Large posters were used on the wall of the room as visual cues. Scheme of the MWM protocol is shown in Fig. 7.

\section{Habituation}

In order to adapt the rats to the MWM test, one day before the starting of training, the rats swam for one minute in a tank without a platform. 


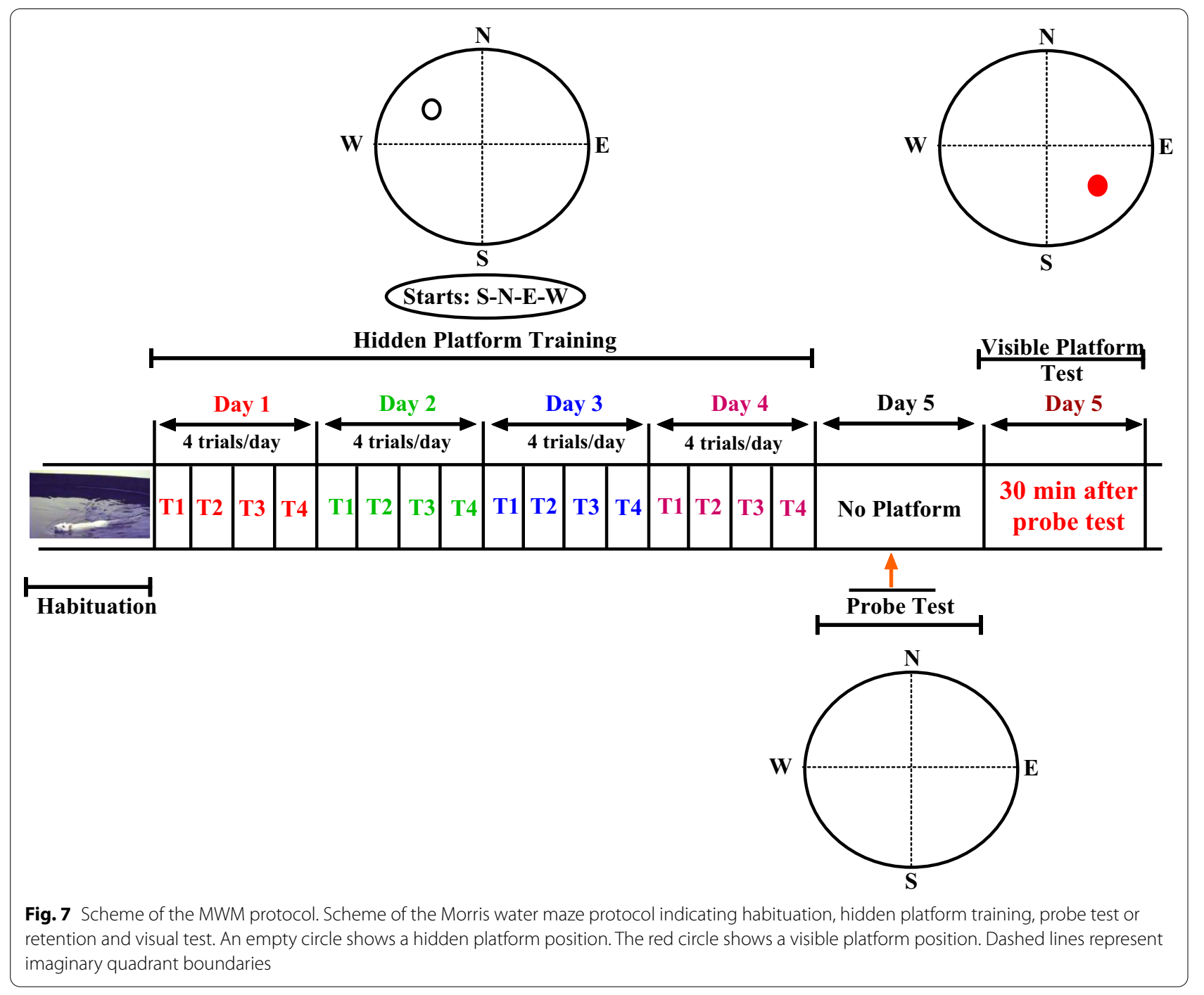

\section{Hidden platform training}

The training sessions were done according to our earlier works [75, 77, 79-81]. Briefly, the training session was conducted for four consecutive days (one block of 4 trials per day). Each trial began by putting the rat in the middle of one of the four quadrants. The swimming time to find the hidden platform was $90 \mathrm{~s}$. If the animal did not find the hidden platform during this period, it was manually transferred to the platform by the investigator. The time between the two consecutive trials was $10 \mathrm{~min}$. To assess acquisition of the MWM task during training days, escape latency (i.e., time to reach the platform) and swimming distance were recorded. The daily average of all trials from day 1 to day 4 was used in our analysis.

\section{Spatial reference memory (Probe test or retention)}

The spatial probe test was performed one day after the last training session. In the spatial probe test, rats swam for $60 \mathrm{~s}$ in a pool without platform. The animals were released into the water in the western quadrant (ie, exactly opposite from where the platform was placed in the training sessions). A video-computer tracking system was used to record the distance traveled and time spent in target zone as well as swimming speed of rats (to evaluate the motor activity).

\section{Visual test}

Thirty minutes after the probe trial, visual test was performed. In the visual test, the platform was covered with bright color aluminum foil and placed in a different zone above the water surface. In the visual test, rats swam for $60 \mathrm{~s}$ to find the visible platform in order to test their visual ability. All experiments were performed between 12:00 and 14:00. 


\section{Surgical procedure, electrophysiological recording and LTP induction}

The procedures used here were done according to our previous works [82-84]. Briefly, after urethane anesthesia $(1.5 \mathrm{~g} / \mathrm{kg}$, i.p), the rats were placed in a stereotaxic device for electrode implantation surgery and field potential recording. Using a heating pad, the temperature of the animals was kept constant at $36.5 \pm 0.5{ }^{\circ} \mathrm{C}$. After the skull is exposed, small holes were drilled in the skull, and then two bipolar stimulating and recording electrodes were implanted in the right cerebral hemisphere. The electrodes were made of Teflon coated stainless steel $(125 \mu \mathrm{m}$ diameter, Advent Co., UK). The coordinates for electrode placement were as follows (according to the Paxinos and Watson atlas of the rat brain $[82,85])$ : Stimulating electrode in the PP [:AP: $-8.1 \mathrm{~mm}$ from bregma; ML: $+4.3 \mathrm{~mm}$ from midline; DV: $3.2 \mathrm{~mm}$ from the skull surface], and recording electrode in the DG granular cell layer [AP: $-3.8 \mathrm{~mm}$ from bregma; ML: $+2.3 \mathrm{~mm}$ from midline; DV: $2.7-$ $3.2 \mathrm{~mm}$ from the skull surface]. To minimize damage to the brain, the electrodes were lowered very slowly $(0.2 \mathrm{~mm} / \mathrm{min})$ from cortex to the hippocampus.

We obtained input-output profile by PP stimulation to determine the intensity of stimulus used in each animal (40\% maximal population spike). Through constant current isolation units (A365 WPI), single $0.1 \mathrm{~ms}$ biphasic square wave pulses were delivered at a frequency of $0.1 \mathrm{~Hz}$. The field potential recordings evoked by stimulation of the PP were recorded extracellularly in the DG area. Test stimuli were delivered to the PP every $10 \mathrm{~s}$. Electrodes were positioned to elicit the maximum amplitude of PS and fEPSP. After recording the steady-state baseline response for $40 \mathrm{~min}$, LTP was induced using the $400 \mathrm{~Hz}$ HFS (including10 bursts of 20 stimuli, $0.2 \mathrm{~ms}$ stimulus duration, $10 \mathrm{~s}$ interburst interval). DG granular neurons were recorded at 5, 30, and $60 \mathrm{~min}$ post-HFS stimulation to determine any change in the both fEPSP and PS. An average of 10 consecutive recordings were made at $10 \mathrm{~s}$ stimulus interval for each time point [83, 86, 87]. For stimulations, stimulus parameters were defined in the software at the beginning and prior delivery to $\mathrm{PP}$, then sent via a data acquisition board connected to a constant current isolator unit (A365 WPI, USA). The evoked responses in the DG region after passing through a preamplifier, were amplified $(1000 \times)$ (Differential amplifier DAM $80 \mathrm{WPI}, \mathrm{USA}$ ), and were filtered (band pass $1 \mathrm{~Hz}$ to $3 \mathrm{kHz}$ ). These responses were digitized at a sampling rate of $10 \mathrm{kHz}$, and were observable on a computer monitor. These responses were stored in a high-speed data storage device for later offline analysis.

\section{Measurement of evoked potentials}

PS and fEPSP are two components of the evoked recording in the DG. In our work, PS amplitude and fEPSP slope were measured. The PS amplitude was measured from the peak of the first positive deflection of the evoked potential to the peak of the following negative potential. The fEPSP slope function was measured as the slope of the line connecting the start of the first positive deflection of the evoked potential with the peak of the second positive deflection of the evoked potential. The stimulation intensity was adjusted to evoke potentials which comprised $40 \%$ of the maximal population spike amplitude, defined by means of an input/output curve $[82,83]$.

\section{Statistical analysis}

GraphPad Prism ${ }^{\circledR}$ 8.0.2 software (San Diego, CA, USA) was used for statistical analysis. Data were presented as means \pm standard error mean (S.E.M.). The data of the training trials in MWM were analyzed using a two-way analysis of variance (ANOVA) (followed by Bonferoni post hoc) with days as repeated measures factor and treatments as between subjects' factor. Student t-test was used for statistical analyses of probe and visibility trial data. Two-way repeated-measures ANOVA followed by Bonferroni post hoc was used for analysis of the LTP data. Student $t$ test was used when only two values were compared. P values below 0.05 were considered statistically significant. The following formula was used to determine LTP values:

$$
\mathrm{LTP}=\frac{\text { the EPSP or PS value after HFS induction } \times 100 \%}{\text { the average EPSP or PS at baseline }}
$$

\section{Acknowledgements}

The authors would like to express their gratitude to the staff of the Neurophysiology Research Center for helping them carry out this project.

\section{Authors' contributions}

SAK supervised the project. SAK, AK, IS, and SS and designed the project, wrote the manuscript and performed the statistical analysis and revised the manuscript. SS, NA, RM, RG and MKA were involved in laboratory works and experimental design of the work. SAK AK, and IS were involved in data collection and lab assessments, and study designing. All authors read and approved the final manuscript.

\section{Funding}

The study was funded by Vice-chancellor for Research and Technology, Hamadan University of Medical Sciences (No. IR.UMSHA.REC.1400.201).

Availability of data and materials

The data are available for any scientific use with kind permission.

\section{Declarations}

Ethics approval and consent to participate

The Animal Study Ethics Committee of our university approved all the experimental procedures used in this study (Code of Ethics Committee: IR.UMSHA. REC.1400.201). Also, all experimental procedures were done in accordance 
with the National Institutes of Health Guide for Care and Use of Laboratory Animals.

\section{Consent for publication}

Not applicable.

\section{Competing interests}

The authors declare that they have no competing interests.

\section{Author details \\ ${ }^{1}$ Neurophysiology Research Center, Hamadan University of Medical Sciences, Hamadan, Iran. ${ }^{2}$ Department of Exercise Physiology, Faculty of Sport Sciences, University of Birjand, Birjand, Iran. ${ }^{3}$ Department of Neuroscience, School of Sci- ence and Advanced Technologies in Medicine, Hamadan University of Medical Sciences, Shahid Fahmideh Street, Hamadan, Iran.}

\section{Received: 12 September 2021 Accepted: 24 October 2021} Published online: 01 November 2021

\section{References}

1. Sickmann H, Patten A, Morch K, Sawchuk S, Zhang C, Parton R, et al. Prenatal ethanol exposure has sex-specific effects on hippocampal longterm potentiation. Hippocampus. 2014;24(1):54-64.

2. Cahill L. Why sex matters for neuroscience. Nat Rev Neurosci. 2006;7(6):477-84.

3. Cosgrove KP, Mazure CM, Staley JK. Evolving knowledge of sex differences in brain structure, function, and chemistry. Biol Psychiat. 2007;62(8):847-55.

4. Chen W, Liu B, Li X, Wang P, Wang B. Sex differences in spatial memory. Neuroscience. 2020;443:140-7.

5. Ellis H. Man and Woman: A Study of Human Secondary Sexual Characteristics (London: Walter Scott). Downloaded from Brill com06/12/2020. 1894;6(24):355.

6. Shah DS, Prados J, Gamble J, De Lillo C, Gibson CL. Sex differences in spatial memory using serial and search tasks. Behav Brain Res. 2013;257:90-9.

7. Woolley DG, Vermaercke B, de Beeck HO, Wagemans J, Gantois I, D'Hooge $R$, et al. Sex differences in human virtual water maze performance: Novel measures reveal the relative contribution of directional responding and spatial knowledge. Behav Brain Res. 2010;208(2):408-14.

8. Astur RS, Ortiz ML, Sutherland RJ. A characterization of performance by men and women in a virtual Morris water task: A large and reliable sex difference. Behav Brain Res. 1998;93(1-2):185-90.

9. Rizk-Jackson AM, Acevedo SF, Inman D, Howieson D, Benice TS, Raber J. Effects of sex on object recognition and spatial navigation in humans. Behav Brain Res. 2006;173(2):181-90.

10. Saucier D, Shultz S, Keller A, Cook C, Binsted G. Sex differences in object location memory and spatial navigation in Long-Evans rats. Anim Cogn. 2008;11(1):129-37.

11. Dabbs JM Jr, Chang E-L, Strong RA, Milun R. Spatial ability, navigation strategy, and geographic knowledge among men and women. Evol Hum Behav. 1998;19(2):89-98.

12. Driscoll I, Hamilton DA, Yeo RA, Brooks WM, Sutherland RJ. Virtual navigation in humans: the impact of age, sex, and hormones on place learning. Horm Behav. 2005;47(3):326-35.

13. Epting LK, Overman WH. Sex-sensitive tasks in men and women: a search for performance fluctuations across the menstrual cycle. Behav Neurosci. 1998;112(6):1304.

14. Lewin C, Wolgers G, Herlitz A. Sex differences favoring women in verbal but not in visuospatial episodic memory. Neuropsychology. 2001;15(2):165

15. lachini T, Sergi I, Ruggiero G, Gnisci A. Gender differences in object location memory in a real three-dimensional environment. Brain Cogn. 2005;59(1):52-9.

16. Persson J, Herlitz A, Engman J, Morell A, Sjölie D, Wikström J, et al. Remembering our origin: gender differences in spatial memory are reflected in gender differences in hippocampal lateralization. Behav Brain Res. 2013;256:219-28.

17. León I, Tascón L, Cimadevilla JM. Age and gender-related differences in a spatial memory task in humans. Behav Brain Res. 2016;306:8-12.
18. Coluccia E, Louse G. Gender differences in spatial orientation: A review. J Environ Psychol. 2004;24(3):329-40.

19. Postma A, Jager G, Kessels RP, Koppeschaar HP, van Honk J. Sex differences for selective forms of spatial memory. Brain Cogn. 2004;54(1):24-34.

20. Rahman $Q$, Bakare $M$, Serinsu C. No sex differences in spatial location memory for abstract designs. Brain Cogn. 2011;76(1):15-9.

21. Blokland A, Rutten K, Prickaerts J. Analysis of spatial orientation strategies of male and female Wistar rats in a Morris water escape task. Behav Brain Res. 2006;171(2):216-24.

22. Méndez-López M, Méndez M, López L, Arias JL. Spatial working memory learning in young male and female rats: involvement of different limbic system regions revealed by cytochrome oxidase activity. Neurosci Res. 2009;65(1):28-34

23. Sandstrom NJ, Kaufman J, Huettel SA. Males and females use different distal cues in a virtual environment navigation task. Cogn Brain Res. 1998;6(4):351-60.

24. Saucier DM, Green SM, Leason J, MacFadden A, Bell S, Elias LJ. Are sex differences in navigation caused by sexually dimorphic strategies or by differences in the ability to use the strategies? Behav Neurosci. 2002;116(3):403.

25. Williams CL, Meck WH. The organizational effects of gonadal steroids on sexually dimorphic spatial ability. Psychoneuroendocrinology. 1991:16(1-3):155-76.

26. Kosaki Y, Lin TCE, Horne MR, Pearce JM, Gilroy KE. The role of the hippocampus in passive and active spatial learning. Hippocampus. 2014:24(12):1633-52.

27. Spellman T, Rigotti M, Ahmari SE, Fusi S, Gogos JA, Gordon JA. Hippocampal-prefrontal input supports spatial encoding in working memory. Nature. 2015;522(7556):309-14.

28. Clark RE, Broadbent NJ, Zola SM, Squire LR. Anterograde amnesia and temporally graded retrograde amnesia for a nonspatial memory task after lesions of hippocampus and subiculum. J Neurosci. 2002;22(11):4663-9.

29. Bliss TV, Collingridge GL. A synaptic model of memory: long-term potentiation in the hippocampus. Nature. 1993;361(6407):31-9.

30. Morris RG, Frey U. Hippocampal synaptic plasticity: role in spatial learning or the automatic recording of attended experience? Philos Trans $R$ Soc Lond B Biol Sci. 1997;352(1360):1489-503.

31. Maren S. Sexually dimorphic perforant path long-term potentiation (LTP) in urethane-anesthetized rats. Neurosci Lett. 1995;196(2):177-80.

32. Maren S, De Oca B, Fanselow MS. Sex differences in hippocampal long-term potentiation (LTP) and Pavlovian fear conditioning in rats: positive correlation between LTP and contextual learning. Brain Res. 1994;661(1):25-34.

33. Yang D-W, Pan B, Han T-Z, Xie W. Sexual dimorphism in the induction of LTP: critical role of tetanizing stimulation. Life Sci. 2004;75(1):119-27.

34. Monfort P, Gomez-Gimenez B, Llansola M, Felipo V. Gender differences in spatial learning, synaptic activity, and long-term potentiation in the hippocampus in rats: molecular mechanisms. ACS Chem Neurosci. 2015;6(8):1420-7.

35. Dursun N, Bayar Y, Buraktan CS, Altuntaş HD. Sex differences in hippocampal long-term depression and the $\mathrm{N}$-methyl-daspartate receptor in rats-positive correlation between LTD and Glun2b subunit. J Neurol Neurosci. 2018. https://doi.org/10.21767/2171-6625.1000267.

36. Helfer JL, White ER, Christie BR. Enhanced deficits in long-term potentiation in the adult dentate gyrus with 2nd trimester ethanol consumption. PLOS ONE. 2012;7(12):e51344.

37. Elmarzouki H, Aboussaleh Y, Bitiktas S, Suer C, Artis AS, Dolu N, et al. Effects of cold exposure on behavioral and electrophysiological parameters related with hippocampal function in rats. Front Cell Neurosci. 2014;8:253.

38. Monfort P, Felipo V. Hippocampal long-term potentiation is reduced in mature compared to young male rats but not in female rats. Neuroscience. 2007;146(2):504-8.

39. Chen L-S, Tzeng W-Y, Chuang J-Y, Cherng CG, Gean P-W, Yu L. Roles of testosterone and amygdaloid LTP induction in determining sex differences in fear memory magnitude. Horm Behav. 2014;66(3):498-508.

40. Bender RA, Zhou L, Vierk R, Brandt N, Keller A, Gee CE, et al. Sex-dependent regulation of aromatase-mediated synaptic plasticity in the basolateral amygdala. J Neurosci. 2017;37(6):1532-45. 
41. Hawley WR, Grissom EM, Barratt HE, Conrad TS, Dohanich GP. The effects of biological sex and gonadal hormones on learning strategy in adult rats. Physiol Behav. 2012;105(4):1014-20.

42. Giedd JN, Vaituzis AC, Hamburger SD, Lange N, Rajapakse JC, Kaysen D, et al. Quantitative MRI of the temporal lobe, amygdala, and hippocampus in normal human development: ages 4-18 years. J Comp Neurol. 1996;366(2):223-30

43. Murphy DG, DeCarli C, Mclntosh AR, Daly E, Mentis MJ, Pietrini P, et al. Sex differences in human brain morphometry and metabolism: an in vivo quantitative magnetic resonance imaging and positron emission tomography study on the effect of aging. Arch Gen Psychiatry. 1996;53(7):585-94.

44. Bueller JA, Aftab M, Sen S, Gomez-Hassan D, Burmeister M, Zubieta J-K. BDNF Val66Met allele is associated with reduced hippocampal volume in healthy subjects. Biol Psychiat. 2006;59(9):812-5.

45. Pruessner JC, Collins DL, Pruessner M, Evans AC. Age and gender predict volume decline in the anterior and posterior hippocampus in early adulthood. J Neurosci. 2001;21(1):194-200.

46. Persson J, Spreng RN, Turner G, Herlitz A, Morell A, Stening E, et al. Sex differences in volume and structural covariance of the anterior and posterior hippocampus. Neuroimage. 2014;99:215-25.

47. Tan A, Ma W, Vira A, Marwha D, Eliot L. The human hippocampus is not sexually-dimorphic: meta-analysis of structural MRI volumes. Neuroimage. 2016;124:350-66

48. Wong M, Moss RL. Patch-clamp analysis of direct steroidal modulation of glutamate receptor-channels. J Neuroendocrinol. 1994;6(3):347-55.

49. Pu S, Xu B, Kalra SP, Kalra PS. Evidence that gonadal steroids modulate nitric oxide efflux in the medial preoptic area: effects of N-methyl-Daspartate and correlation with luteinizing hormone secretion. Endocrinology. 1996;137(5):1949-55.

50. Romeo RD, McCarthy JB, Wang A, Milner TA, McEwen BS. Sex differences in hippocampal estradiol-induced N-methyl-D-aspartic acid binding and ultrastructural localization of estrogen receptor-alpha. Neuroendocrinology. 2005;81(6):391-9.

51. Qi X, Zhang K, Xu T, Yamaki VN, Wei Z, Huang M, et al. Sex differences in long-term potentiation at temporoammonic-CA1 synapses: potential implications for memory consolidation. PLOS ONE. 2016;11(11):e0165891.

52. Reisel D, Bannerman DM, Schmitt WB, Deacon RM, Flint J, Borchardt T, et al. Spatial memory dissociations in mice lacking GluR1. Nat Neurosci. 2002:5(9):868-73

53. Jeffery KJ, Morris RG. Cumulative long-term potentiation in the rat dentate gyrus correlates with, but does not modify, performance in the water maze. Hippocampus. 1993;3(2):133-40.

54. Moser El, Krobert KA, Moser M-B, Morris RG. Impaired spatial learning after saturation of long-term potentiation. Science. 1998;281(5385):2038-42.

55. Chater TE, Goda Y. The role of AMPA receptors in postsynaptic mechanisms of synaptic plasticity. Front Cell Neurosci. 2014;8:401.

56. Serulle Y, Zhang S, Ninan I, Puzzo D, McCarthy M, Khatri L, et al. A GluR1-cGKII interaction regulates AMPA receptor trafficking. Neuron. 2007;56(4):670-88.

57. Morris R, Anderson E, Lynch GA, Baudry M. Selective impairment of learning and blockade of long-term potentiation by an N-methyl-D-aspartate receptor antagonist, AP5. Nature. 1986;319(6056):774-6.

58. Morris RG, Moser E, Riedel G, Martin S, Sandin J, Day M, et al. Elements of a neurobiological theory of the hippocampus: the role of activitydependent synaptic plasticity in memory. Philos Trans R Soc Lond B Biol Sci. 2003;358(1432):773-86.

59. Sanderson DJ, Good MA, Seeburg PH, Sprengel R, Rawlins JNP, Bannerman DM. The role of the GluR-A (GluR1) AMPA receptor subunit in learning and memory. Prog Brain Res. 2008;169:159-78.

60. Yagi S, Galea LA. Sex differences in hippocampal cognition and neurogenesis. Neuropsychopharmacology. 2019;44(1):200-13.

61. Jonasson Z. Meta-analysis of sex differences in rodent models of learning and memory: a review of behavioral and biological data. Neurosci Biobehav Rev. 2005;28(8):811-25.

62. Perrot-Sinal TS, Kostenuik MA, Ossenkopp K-P, Kavaliers M. Sex differences in performance in the Morris water maze and the effects of initial nonstationary hidden platform training. Behav Neurosci. 1996;110(6):1309.

63. Beiko J, Lander R, Hampson E, Boon F, Cain DP. Contribution of sex differences in the acute stress response to sex differences in water maze performance in the rat. Behav Brain Res. 2004;151(1-2):239-53.
64. Engelmann M, Ebner K, Landgraf R, Wotjak CT. Effects of Morris water maze testing on the neuroendocrine stress response and intrahypothalamic release of vasopressin and oxytocin in the rat. Horm Behav. 2006;50(3):496-501.

65. Healy $S, D^{\prime}$ Eath $R$, Harris A. Sex differences in spatial cognition are not caused by isolation housing. Behaviour. 2008;145(6):757-78.

66. Harris AP, D'eath RB, Healy SD. Sex differences, or not, in spatial cognition in albino rats: acute stress is the key. Anim Behav. 2008;76(5):1579-89.

67. Herrero Al, Sandi C, Venero C. Individual differences in anxiety trait are related to spatial learning abilities and hippocampal expression of mineralocorticoid receptors. Neurobiol Learn Mem. 2006;86(2):150-9.

68. Harris AP, D'Eath RB, Healy SD. Environmental enrichment enhances spatial cognition in rats by reducing thigmotaxis (wall hugging) during testing. Anim Behav. 2009;77(6):1459-64.

69. Bayer J, Gläscher J, Finsterbusch J, Schulte LH, Sommer T. Linear and inverted U-shaped dose-response functions describe estrogen effects on hippocampal activity in young women. Nat Commun. 2018;9(1):1-12.

70. Hampson E. Estrogen-related variations in human spatial and articulatory-motor skills. Psychoneuroendocrinology. 1990;15(2):97-111.

71. Viau V, Meaney M. Basal and stress hypothalamic pituitary adrenal activity in cycling and ovariectomized steroid treated rats. Endocrinology. 1992;131:1261-9.

72. Mizuno K, Antunes-Martins A, Ris L, Peters M, Godaux E, Giese K. Calcium/ calmodulin kinase kinase $\beta$ has a male-specific role in memory formation. Neuroscience. 2007:145(2):393-402.

73. Peters M, Mizuno K, Ris L, Angelo M, Godaux E, Giese KP. Loss of Ca2+/ calmodulin kinase kinase $\beta$ affects the formation of some, but not all, types of hippocampus-dependent long-term memory. J Neurosci. 2003:23(30):9752-60

74. Dachtler J, Hardingham NR, Fox K. The role of nitric oxide synthase in cortical plasticity is sex specific. J Neurosci. 2012;32(43):14994-9.

75. Karimi SA, Hosseinmardi N, Janahmadi M, Sayyah M, Hajisoltani R. The protective effect of hydrogen sulfide (H2S) on traumatic brain injury (TBI) induced memory deficits in rats. Brain Res Bull. 2017;134:177-82.

76. Hajisoltani R, Karimi SA, Rahdar M, Davoudi S, Borjkhani M, Hosseinmardi $\mathrm{N}$, et al. Hyperexcitability of hippocampal CA1 pyramidal neurons in male offspring of a rat model of autism spectrum disorder (ASD) induced by prenatal exposure to valproic acid: a possible involvement of Ih channel current. Brain Res. 2019;1708:188-99.

77. Habibitabar E, Moridi H, Shateri H, Karimi SA, Salehi I, Komaki A, et al. Chronic NaHS treatment improves spatial and passive avoidance learning and memory and anxiety-like behavior and decreases oxidative stress in rats fed with a high-fat diet. Brain Res Bull. 2020. https://doi.org/10.1016/j. brainresbull.2020.09.007.

78. Moridi H, Sarihi A, Habibitabar E, Shateri H, Salehi I, Komaki A, et al. Effects of post-training administration of LY341495, as an $\mathrm{mGluR2/3}$ antagonist on spatial memory deficit in rats fed with high-fat diet. IBRO Reports. 2020;9:241-6.

79. Omidi G, Karimi SA, Rezvani-Kamran A, Monsef A, Shahidi S, Komaki A. Effect of coenzyme Q10 supplementation on diabetes induced memory deficits in rats. Metab Brain Dis. 2019. https://doi.org/10.1007/ s11011-019-00402-7.

80. Karimi SA, Salehi I, Shykhi T, Zare S, Komaki A. Effects of exposure to extremely low-frequency electromagnetic fields on spatial and passive avoidance learning and memory, anxiety-like behavior and oxidative stress in male rats. Behav Brain Res. 2019;359:630-8.

81. Rezagholizadeh A, Karimi SA, Hosseinmardi N, Janahmadi M, Sayyah $M$. The effects of glial cells inhibition on spatial reference, reversal and working memory deficits in a rat model of traumatic brain injury (TBI). Int J Neurosci. 2020. https://doi.org/10.1080/00207454.2020.1807544.

82. Karimi SA, Salehi I, Komaki A, Sarihi A, Zarei M, Shahidi S. Effect of high-fat diet and antioxidants on hippocampal long-term potentiation in rats: an in vivo study. Brain Res. 2013;1539:1-6.

83. Karimi SA, Komaki A, Salehi I, Sarihi A, Shahidi S. Role of group II metabotropic glutamate receptors ( $\mathrm{mGluR2/3)}$ ) blockade on long-term potentiation in the dentate gyrus region of hippocampus in rats fed with high-fat diet. Neurochem Res. 2015;40(4):811-7.

84. Karimi SA, Komaki S, Taheri M, Omidi G, Kourosh-Arami M, Salehi I, et al. Effects of the hydroalcoholic extract of Rosa damascena on hippocampal long-term potentiation in rats fed high-fat diet. J Physiol Sci. 2021;71(1):1-9. 
85. Paxinos $G$, Watson $C$. The rat brain in stereotaxic coordinates. Cambridge: Elsevier Academic Press; 2005

86. Taube JS, Schwartzkroin PA. Mechanisms of long-term potentiation: a current-source density analysis. J Neurosci. 1988;8(5):1645-55.

87. Salehi I, Komaki A, Karimi SA, Sarihi A, Zarei M. Effect of garlic powder on hippocampal long-term potentiation in rats fed high fat diet: an in vivo study. Metab Brain Dis. 2018;33(3):725-31.

\section{Publisher's Note}

Springer Nature remains neutral with regard to jurisdictional claims in published maps and institutional affiliations.
Ready to submit your research? Choose BMC and benefit from:

- fast, convenient online submission

- thorough peer review by experienced researchers in your field

- rapid publication on acceptance

- support for research data, including large and complex data types

- gold Open Access which fosters wider collaboration and increased citations

- maximum visibility for your research: over $100 \mathrm{M}$ website views per year

At BMC, research is always in progress.

Learn more biomedcentral.com/submissions 